\title{
RARE EARTH COORDINATION ENVIRONMENTS IN ULTRAPHOSPHATE GLASSES
}

\author{
RICHARD K. BROW and ANDREW K. WITTENAUER \\ Ceramic Engineering Department, University of Missouri-Rolla, Rolla, MO 65409 , \\ USA
}

\begin{abstract}
Rare earth phosphate glasses with molar compositions $\mathrm{xRE}_{2} \mathrm{O}_{3}(1-\mathrm{x}) \mathrm{P}_{2} \mathrm{O}_{5}$ $(0 \leq \mathrm{x} 0.30)$ were prepared and characterized by extended $\mathrm{x}$-ray absorption fine structure (EXAFS) spectroscopy and by high-energy $x$-ray diffraction (XRD) analyses. The analyses indicate that the average coordination number $(\mathrm{CN})$ of the $\mathrm{RE}^{3+}$ ions depends on composition: ultraphosphate glasses with less than $\sim 15$ mole\% $\mathrm{RE}_{2} \mathrm{O}_{3}$ have average $\mathrm{RE} C \mathrm{CN}$ 's of $8-9$ and $\mathrm{CN}$ decreases to $\sim 6$ with increasing $\mathrm{RE}_{2} \mathrm{O}_{3}$ content to $25 \mathrm{~mole} \%$. The compositional dependence of RE CN can be understood with a simple model in which the formation of structurally isolated RE-polyhedra is favored in ultraphosphate glasses. Glass properties, including refractive index and glass transition temperature, are sensitive to changes in glass structure.
\end{abstract}

\section{Introduction}

Structural information about the local coordination environments of rare earth (RE) ions in phosphate glasses is interesting because of the use of these materials in lasers and optoelectronic components ${ }^{1}$. Binary rare earth phosphate glasses can be made with over 25 mole\% $\mathrm{RE}_{2} \mathrm{O}_{3}$ and these glasses possess interesting luminescent and magnetic properties. There have been a number of studies on the structure of binary rare earth phosphate glasses, including Extended X-ray Absorption Fine Structure (EXAFS) spectroscopy and neutron and $x$-ray diffraction ${ }^{2,3,4,5}$. Because of the volatility of $\mathrm{P}_{2} \mathrm{O}_{5}$ from phosphate-rich melts, most of these investigations involved only glasses with compositions close to the RE metaphosphates (25 mole\% $\mathrm{RE}_{2} \mathrm{O}_{3}$ ). Studies of the structures of $\mathrm{RE}$ ultraphosphate ( $<25$ mole $\% \mathrm{RE}_{2} \mathrm{O}_{3}$ ) glasses are much more limited ${ }^{6}$. Such studies are warranted, however, because of the useful laser $^{7}$ and ferroelastic ${ }^{8}$ properties of ultraphosphate crystals $\left(\mathrm{REP}_{5} \mathrm{O}_{14}\right)$.

We have recently reported EXAFS $^{9}$ and high-energy $x$-ray diffraction $(\mathrm{XRD})^{10}$ analyses of rare earth ultraphosphate glasses. These studies indicate that the coordination environments of RE ions depend on the glass composition. 


\section{Experimental Procedures}

Ultraphosphate glasses were prepared from mixtures of vacuum-purified $\mathrm{P}_{2} \mathrm{O}_{5}$ and $\mathrm{La}_{2} \mathrm{O}_{3}, \mathrm{NdPO}_{4}, \mathrm{GdPO}_{4}$, and $\mathrm{ErPO}_{4}$ handled in an argon dry-box and sealed in flame-dried silica ampoules to prevent $\mathrm{P}_{2} \mathrm{O}_{5}$ volatilization. The samples were heated to $1000-1100^{\circ} \mathrm{C}$, depending on composition, for twenty minutes until a homogeneous liquid was formed. The ampoules were then transferred to the dry-box before separating the $\mathrm{RE}$-glasses. Glasses with more than 20 mole $\% \mathrm{RE}_{2} \mathrm{O}_{3}$ were prepared by melting oxide mixtures in covered silica crucibles at $1250^{\circ} \mathrm{C}$ for thirty minutes. Glass compositions were determined using analytical electron microscopy. The analyzed RE/P ratios were in close agreement with the batched compositions and the glasses contain up to $\sim 6$ mole $\% \mathrm{SiO}_{2}$. Refractive indices were measured using comparative index oils and are accurate to \pm 0.002 . Glass transition temperatures $\left(T_{g}\right)$ were measured by differential scanning calorimetry, heating at $10^{\circ} \mathrm{C} / \mathrm{min}$ in an inert atmosphere after first cooling samples through the glass transformation range at $-10^{\circ} \mathrm{C} / \mathrm{min}$ to fix the thermal history; the $\mathrm{T}_{\mathrm{g}}$ 's are reproducible to $\pm 4^{\circ} \mathrm{C}$.

Room-temperature $\mathrm{L}_{\mathrm{Im}}$-edge EXAFS spectra were collected at the Stanford Synchrotron Radiation Laboratory using a half-tuned $\mathrm{Si}(220)$ double-crystal monochromator. Samples were prepared and analyzed using procedures described elsewhere9:11. The X-ray diffraction experiments were performed on the BW5 wiggler beamline at the DORIS III synchrotron (Hamburg/Germany), as described by Hoppe et al10.

\section{Results and. Discussion}

FIGURE 1 shows the refractive indices of several series of RE-phosphate glasses. In general, the refractive index increases with increasing $\mathrm{RE}_{2} \mathrm{O}_{3}$ contents, although for each series, increasing $\mathrm{RE}_{2} \mathrm{O}_{3}$ between about 15 and 25 mole\% has less of an effect on $n$.

FIGURE 2 shows the glass transition temperatures of the $\mathrm{Nd}$ and $\mathrm{Gd}$-phosphate glasses as well as the $T_{\mathrm{g}}$ 's reported for a series of $\mathrm{Li}-\mathrm{ultraphosphate}$ glasses ${ }^{12}$, plotted against the oxygen-to-phosphorus ratio, determined from the respective glass compositions. Each series, including the Li-ultraphosphates, reveals a minimum in $\mathrm{T}_{\mathrm{g}}$ at $\mathrm{O} / \mathrm{P} \approx 2.6-2.7\left(\sim 7\right.$ mole\% $\left.\mathrm{RE}_{2} \mathrm{O}_{3}\right)$. Similar results have been reported for the Laglasses. $^{13}$ 


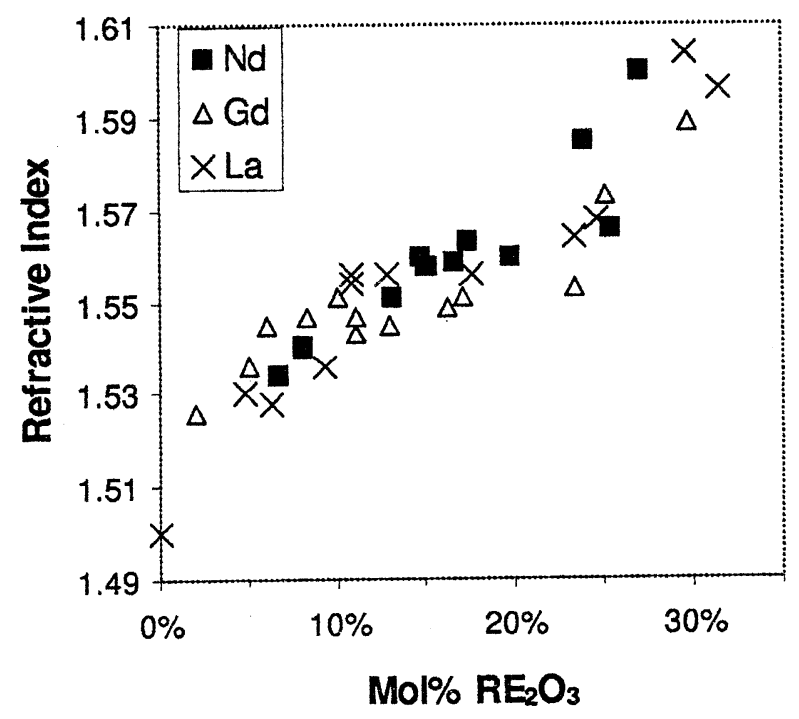

FIGURE 1: Refractive indices of $\mathrm{La}-, \mathrm{Nd}-$, and $\mathrm{Gd}-$ phosphate glasses.

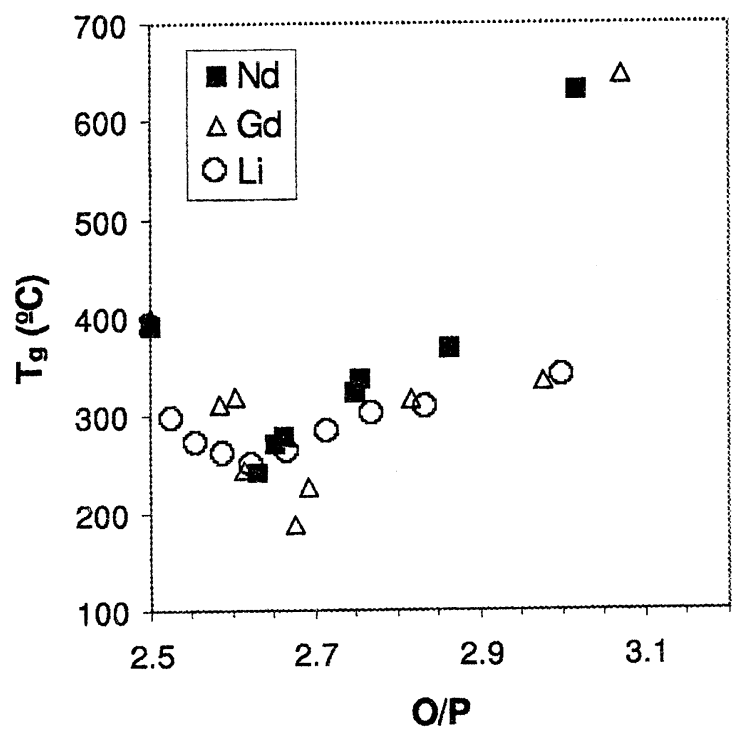

FIGURE 2: Glass transition temperatures for Nd- and Gd--phosphate glasses and for a set of $\mathrm{Li}$-phosphate glasses reported by Hudgens and Martin12. 
FIGURE 3 shows the $\mathrm{Nd}$ and Er coordination numbers determined from the EXAFS experiments9 and from high-resolution $\mathrm{x}$-ray diffraction analyses of Laphosphate glasse10s and $\mathrm{Nd}$-phosphate glass5es. There are $\sim 8-9$ oxygens coordinating the $\mathrm{RE}$ ions in glasses containing less than $\sim 15 \mathrm{~mol} \% \mathrm{RE}_{2} \mathrm{O}_{3}$. The $\mathrm{RE}$ $\mathrm{CN}$ decreases to $\sim 6$ for glasses with $>25$ mole $\% \mathrm{RE}_{2} \mathrm{O}_{3}$.

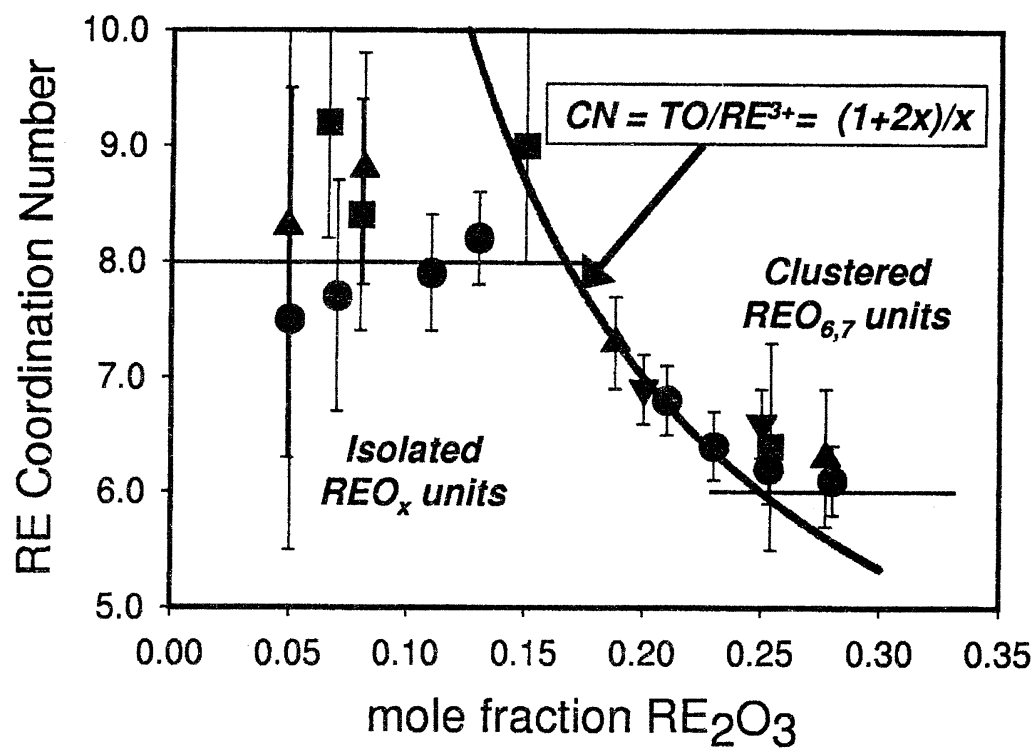

FIGURE 3: Coordination numbers determined from the EXAFS spectra9 from Nd(7) and Er- (p) phosphate glasses and XRD analyses of La10- (5) and N5d-(q) phosphate glasses. The solid line is calculated from equation 1.

Hoppe et al. have proposed that the structures and properties of ultraphosphate glasses are dependent on the number of terminal oxygens available to coordinate the modifier ions $3^{, 14}$. For glasses with the stoichiometry $x\left(\mathrm{M}_{2 / \mathrm{v}} \mathrm{O}\right)-(1-\mathrm{x}) \mathrm{P}_{2} \mathrm{O}_{5}$, where $\mathrm{M}$ is a metal modifier and $\mathrm{v}$ is the valence of the modifier ion, the number of terminal oxygens per modifying ion is $M_{T O}=v(1 / x)$. This equation can be re-written for $\mathrm{xRE}_{2} \mathrm{O}_{3}-(1-\mathrm{x}) \mathrm{P}_{2} \mathrm{O}_{5}$ glasses to determine the dependence of the number of terminal oxygens per $\mathrm{RE}^{3+}$ ion on the mole fraction $(\mathrm{x})$ of $\mathrm{RE}_{2} \mathrm{O}_{3}$ :

$$
\mathrm{TO} / \mathrm{RE}^{3+}=(1+2 \mathrm{x}) / \mathrm{x}
$$

There are at least two structurally sensitive compositional ranges 14 that are defined by the $\mathrm{RE}$ coordination number $\left(\mathrm{CN}_{\mathrm{RE}}\right)$ and the number of terminal oxygens $\left(\mathrm{TO} / \mathrm{RE}^{3+}\right)$. When $\mathrm{TO} / \mathrm{RE}^{3+}>\mathrm{CN}_{\mathrm{RE}}$, there are sufficient terminal oxygens to form 
isolated RE coordination polyhedra within the phosphate network, as are found in crystalline $\mathrm{NdP}_{5} \mathrm{O}_{14}$ and $\mathrm{ErP}_{5} \mathrm{O}_{14 .}{ }^{15,16}$ When TO/RE' ${ }^{3+}<\mathrm{CN}_{\mathrm{RE}}$, there are not enough terminal oxygens available to satisfy the coordination requirements of isolated $\mathrm{RE}$ ions and so these ions must share the available terminal oxygens through $\mathrm{RE}-\mathrm{O}-\mathrm{RE}$ linkages.

The EXAFS and XRD results indicate that there is a decrease in the RE coordination number (and a reduction in the average $\mathrm{RE}-\mathrm{O}$ bond length910) with increasing $\mathrm{RE}_{2} \mathrm{O}_{3}$ (FIGURE 3). According to equation (1), isolated eightcoordinated $\mathrm{RE}^{3+}$ ions, like those found in the $\mathrm{REP}_{5} \mathrm{O}_{14}$ crystals, can exist in $\mathrm{xRE}_{2} \mathrm{O}_{3} \cdot(1-\mathrm{x}) \mathrm{P}_{2} \mathrm{O}_{5}$ glasses when $\mathrm{x} \leq 0.167$. Isolated $\mathrm{RE}-$ polyhedra can also exist in glasses with greater $\mathrm{RE}_{2} \mathrm{O}_{3}$ contents only if the average $\mathrm{RE}$ coordination number decreases. The solid line in FIGURE 3 is the predicted dependence according to equation 1. Note that for coordination numbers and compositions to the left of (and below) the line, isolated polyhedra are expected to be present. Clustered REpolyhedra sharing common oxygens will result for $\mathrm{CN} /$ composition combinations to the right of (and above) the line. The decrease in RE CN between $~ 15$ and 25 mole\% $\mathrm{RE}_{2} \mathrm{O}_{3}$ and thus avoids the formation of $\mathrm{RE}$-clusters in glasses with increasing $\mathrm{RE}_{2} \mathrm{O}_{3}$. Note that equation 1 predicts that when $\mathrm{RE}_{2} \mathrm{O}_{3}$ exceeds 25 mole\%, CN must fall below six in order for the RE-polyhedra to remain isolated. It is unlikely that these large ions possess coordination numbers under six, and so RE-clusters are expected to be present in glasses with $\mathrm{RE}_{2} \mathrm{O}_{3}$ contents $>25$ mole $\%$.

Breaks in the compositional dependence of the refractive index near $\sim 15$ mole $\%$ and 25 mole\% $\mathrm{RE}_{2} \mathrm{O}_{3}$ (FIGURE 1) are consistent with this structural model and indicate the range over which the average $\mathrm{RE} C N$ decreases to avoid clustering. The minimum in $\mathrm{T}_{\mathrm{g}}$, near 7 mole $\% \mathrm{RE}_{2} \mathrm{O}_{3}(\mathrm{O} / \mathrm{P} 2.7)$, occurs outside of this compositional range. High-energy $\mathrm{x}$-ray diffraction analyses of La-ultraphosphate glasses10 indicate a possible change in ordering between La-polyhedra and P-tetrahedra near 7 mole $\% \mathrm{La}_{2} \mathrm{O}_{3}$. The presence of a $\mathrm{T}_{\mathrm{g}}$ minimum at a similar $\mathrm{O} / \mathrm{P}$ ratio for the $\mathrm{Li}-$ ultraphosphate glass series indicates that this minimum depends on the phosphate network and is less sensitive to the nature of the modifying ions.

\section{Acknowledgements}

We acknowledge the donors of The Petroleum Research Fund, administered by the American Chemical Society, for support of this research. We thank our colleagues Kanishka Marasinghe (University of North Dakota), Mevlut Karabulut 
(University of Kafkas, Kars, Turkey), Uwe Hoppe (Rostock University), Ezz Metwalli (National Research Centre, Cairo, Egypt), and Clarissa Vierrether (UMR) for their contributions to this study.

\section{$\underline{\text { References }}$}

J.H. Campbell, T.I Suratwala, J. Non-Cryst. Solids, 263/264, 318 (2000).

- T. Brennan, J.C. Knight, G.A. Saunders, Phys. Chem. Glasses, 40, 113 (1999).

- U. Hoppe, R. Kranold, D. Stachel, A. Barz, A.C. Hannon, J. Non-Cryst. Solids, 232/234. 44. (1998).

D.T. Bowron, G.A. Saunders, R.J. Newport, B.D. Rainford, H.B. Senin, Phys. Rev B. $\underline{53}$, 5268. (1996).

U. Hoppe, H. Ebendorff-Heidepriem, J. Neuefeind, D.T. Bowron, Zeitsch. f. Naturforsch A-A J. Phys. Sci. 56, 237-243, (2001).

G. Mountjoy, J.M. Cole, T. Brennan, R.J. Newport, G.A. Saunders, G.W. Wallidge, J. Non-Cryst. Solids, 279, 20. (2001).

7 . H.P. Weber, T.C. Damen, H.G. Danielmeyer, B.C. Tofield, Appl. Phys. Lett., $22,534$. (1973).

$8 \quad$. H.P. Weber, B.C. Tofield, P.F. Liao, P.F., Phys. Rev. B, 11, 1152 (1975).

9 . M. Karabulut, G.K. Marasinghe, E. Metwalli, A. K. Wittenauer, R.K. Brow, C.H. Booth, J.J. Bucher, D.K. Shuh, Physical Review B 65, 104206-1 (2002).

10 . U. Hoppe, E. Metwalli, R. K. Brow, J. Neuefeind, J. Non-Cryst. Solids, 297263 (2002).

11 . M.Karabulut, G.K. Marasinghe, C.S. Ray, D.E. Day, G.D. Waddill, C.H. Booth, J.J. Bucher, D.L. Caulder, D.K. Shuh, P.G. Allen, M. Grimsditch, M., J. Mater. Res., 15, 1972 (2000).

12 . J. J. Hudgens, S.W. Martin, J. Am. Ceram. Soc., 76, 1691 (1993).

${ }_{13}$. R. K. Brow, E. Metwalli, D. L. Sidebottom, in Inorganic Optical Materials II. Proceedings of the International $45^{\text {th }}$ Annual Meeting of the SPIE, 4102, 88 (2000).

14 . U. Hoppe, J. Non-Cryst. Solids, 195, 138 (1996).

$15 \quad$. H.Y-P. Hong, Acta Cryst. B 30, 468 (1974).

16 . B. J. Trzebiatowska, Z. Mazurak, Acta Cryst. B, $\underline{36}, 1639$ (1980). 